\title{
Overexpression of Bax sensitizes prostate cancer cells to TGF- $\beta$ induced apoptosis
}

\author{
Pei Hui LIN ${ }^{1}$, Zui PAN ${ }^{1}$, Lin $Z_{\text {HENG }}^{1}, \mathrm{Na} \mathrm{LI}^{1}$, David DANIELPOUR ${ }^{2}$, Jian Jie MA ${ }^{1, *}$ \\ ${ }^{1}$ Department of Physiology and Biophysics, Robert Wood Johnson Medical School, 675 Hoes Lane, Piscataway, NJ 08854, USA \\ ${ }^{2}$ Ireland Cancer Center, Case Western Reserve University, 10900 Euclid Avenue, Cleveland, OH 44106, USA
}

\begin{abstract}
NRP-154 is a tumorigenic epithelial cell line derived from the preneoplastic dorsal-lateral prostate of rats. These cells are exquisitely sensitive to TGF- $\beta$ induced apoptosis. In contrast, we find that NRP- 154 cells can sustain overexpression of exogenous Bax protein, which is different from non-tumor cells where Bax functions as a ubiquitous stimulator of apoptosis. NRP-154 cells stably overexpressing Bax show increased sensitivity to TGF- $\beta$ induced apoptosis. The degree of TGF- $\beta$ induced apoptosis displays high correlation with cleavage of Bax at the amino-terminus. Our data indicate that prostate cancer cells can host high levels of latent Bax which can be activated through post-translational modification.
\end{abstract}

Keywords: NRP-154 cells, prostate cancer, Bax, TGF- $\beta$, apoptosis.

\section{INTRODUCTION}

Adenocarcinoma of the prostate is a leading threat to men's health. Prostate cancer mortality results from metastases to the bone and lymph nodes together with progression from androgen-dependent to androgen independent disease [1]. Numerous factors influence the survival of prostate cancer cells. Transforming growth factor- $\beta 1$ (TGF- $\beta$ ) is a multifunctional cytokine which regulates cell proliferation, differentiation and apoptosis [2]. Bcl-2 family proteins are critical regulators of apoptosis in a variety of tissues, including prostate cancer cells, which share conserved Bcl-2 homology (BH) domains and comprise mainly three groups of proteins: anti-apoptotic members (e.g. Bcl-2, Bcl-xL), pro-apoptotic members (e.g. Bax, Bak) and regulatory BH3-domain-only members (Hrk, Bad, Bid) (for review [3]). Latent Bax, a pro-apoptotic molecule, is largely cytosolic or loosely associates with intracellular membranes. In response to apoptotic stimuli, Bax undergoes a conformational change, leading to its integration into the mitochondrial outer membrane or endoplasmic reticulum [4]. The membrane translocalization of Bax triggers a number of changes in cellular homeo-

\footnotetext{
*correspondence: Jian Jie MA

Tel: +732-235-4494; Fax: +732-235-4483;

E-mail: maj2@umdnj.edu
}

stasis, including perturbation of intracellular $\mathrm{Ca}^{2+}$ and mitochondrial dysfunction, followed by downstream activation of caspases. Recent studies have suggested that posttranslational modification of Bax, e.g. calpain-mediated cleavage at its amino terminus, play an important role in the apoptotic-cascade of a number of cell types [5-8]. Proteolytic cleavage of Bax by calpain leads to the generation of p18-Bax, which could function as a BH3-domain only protein with more potent apoptotic functions [9].

Research in prostate cancer has been limited by the availability of appropriate cell lines. There are only a few human prostatic cell lines in ATCC (American Type Culture Collection), all of which were derived from metastases. In this study we used an androgen-independent, tumorigenic epithelial cell line (NRP-154) that was derived from the preneoplastic dorsal-lateral prostate of Lobund/Wistar rats, a strain that has an unusually high incidence of cancers of the male reproductive system [10]. NRP-154 cells have luminal cell phenotype and are exquisitely sensitive to TGF$\beta$ induced apoptosis, and thus provide a useful model to examine the apoptotic signaling cascade in prostate cancer.

Here we identify a surprising and unique property of NRP-154 cells. In contrast to most other known non-tumor cells where Bax has been described as a consistant stimulator of apoptosis, sustained and stable over-expression of Bax (up to 10 fold over endogenous levels) can be achieved in NRP-154 cells without induction of apoptosis. Such re- 
sult raises an intriguing possibility that other co-factors may exist in NRP-154 cells to regulate the apoptotic effect of Bax, and could thus be responsible for the tumorigenic growth of prostate tissues. We further show that NRP-154 cells overexpressing latent Bax become more sensitive to TGF- $\beta$ induced apoptosis. Our data supports the concept of Bax-mediated therapy of prostate cancer, and also provides additional insights into the modulatory function of Bax in apoptosis.

\section{MATERIALS AND METHODS}

\section{Subcloning}

cDNA encoding the mouse Bax was subcloned into the pCEP4 expression vector (Invitrogen, Carlsbad, CA) between the NheI and Not $\mathrm{I}$ restriction sites. The GFP-Bax fusion construct was generated as described previously [11].

\section{Cell culture and transfection}

NRP-154 cells were maintained in D-MEM/F-12 media supplemented with $10 \%$ fetal bovine serum, $2 \mathrm{mM}$ glutamine, $15 \mathrm{mM}$ HEPES buffer and $1 \%$ penicillin-streptomycin (Invitrogen) under subconfluent conditions. pCEP4(Bax) or pCDNA3-(GFP-Bax) were transfected into NRP-154 cells using the Lipofectamine 2000 reagent (Invitrogen). NRP-154 cells overexpressing Bax were selected with hygromycin $(250 \mu \mathrm{g} / \mathrm{ml})$, and individual stable clones were established using limited dilution methods. As controls, NRP-154 cells were transfected with the empty pCEP4 plasmid, subjected to hygromycin selection, and treated in the same way as the pCEP4 (Bax) transfected cells.

\section{TGF- $\beta$ treatment}

Recombinant human TGF- $\beta 1$ was obtained from R \& D Systems (Minneapolis, MN) and acid-activated TGF- $\beta 1$ was prepared as instructed. Briefly, lyophilized TGF- $\beta 1$ was reconstituted with sterile $4 \mathrm{mM} \mathrm{HCl}$ containing $1 \mathrm{mg} / \mathrm{ml}$ BSA (Fraction V, Sigma, St. Louis, $\mathrm{MO})$ to a final stock concentration of $10 \mu \mathrm{g} / \mathrm{ml}$, aliquoted and stored at $-80^{\circ} \mathrm{C}$. $1.5 \times 10^{6}$ cells were seeded onto $\mathrm{T} 75$ flasks and cultured for $24 \mathrm{~h}$ to reach $30 \%-40 \%$ confluence. Then TGF- $\beta(10 \mathrm{ng} / \mathrm{ml})$ was added to the cells in D-MEM/F-12 media containing $1 \%$ fetal bovine serum and $0.1 \mu \mathrm{M}$ dexamethasome (Sigma). Apoptosis was measured $48 \mathrm{~h}$ later.

\section{Western blotting}

For Western blotting analysis, whole cell lysates were prepared with RIPA buffer ( $150 \mathrm{mM} \mathrm{NaCl}, 20 \mathrm{mM} \mathrm{NaH}_{2} \mathrm{PO}_{4}, 50 \mathrm{mM} \mathrm{NaF}$, 2 mM EDTA, $0.1 \%$ SDS, $1 \%$ Deoxycholic Acid, $1 \%$ Triton X-100, $\mathrm{pH}$ 7.2) in the presence of a protease inhibitor cocktail (Sigma). Equal amounts of protein $(40 \mu \mathrm{g})$ were resolved using $10 \%$ sodium dodecyl sulfate-polyacrylamide gel electrophoresis (SDS-PAGE) (Novex, Invitrogen). Antibodies used include the following, monoclonal anti-Bax 6A7 (1: 1000 dilution, Zymed Laboratories, South San Francisco, CA); polyclonal anti-Bax $\Delta 21$ (1: 1000 dilution, Santa Cruz Biotechnology, Santa Cruz, CA); Anti- $\beta$-actin (Sigma). Horseradish peroxidase-conjugated secondary antibodies (Pierce Biotechnology, Rockford, IL) were applied and chemiluminescence was detected with ECL Plus (Amersham, Piscataway, NJ). Relative protein expression level was quantitatively analyzed via Hitachi scanning densitometry with Hitachi GeneTools CCD-BIO software
(Hitachi Software/Engineering Co., San Jose, CA).

\section{Confocal microscopy imaging}

For subcellular localization of transiently expressed GFP-Bax, NRP-154 cells were grown on glass-bottomed $\triangle \mathrm{TC} 3$ dishes (Bioptechs, Inc., Butler, PA) and visualized with a Zeiss LSM-510 laser scanning microscope using a Plan-Apochromat $63 \times$ oil or CApochromat $40 \times$ water immersion objective.

\section{TUNEL assay}

TdT-mediated dUTP Nick End Labeling (TUNEL) assay was performed using ApopTag Fluorescein In Situ Apoptosis Detection Kit (Intergen Company, Purchase, NY). Briefly, the NRP-154 cell lines were grown on glass-bottomed $\triangle \mathrm{TC} 3$ dishes and treated with TGF- $\beta$ as described above. Cells were first washed in equilibration buffer, incubated with TdT enzyme in a humidified chamber at $37^{\circ} \mathrm{C}$ for $1 \mathrm{~h}$; cells were then washed and incubated (RT, $30 \mathrm{~min}$ ) in the dark with fluorescein-conjugated anti-digoxigenin . The washed specimens were counterstained with Propidium Iodide $(1 \mu \mathrm{g} / \mathrm{ml})$ and visualized with Zeiss AxioVision fluorescent microscope.

\section{DNA fragmentation assay}

Cells were resuspended in a buffer containing $0.15 \mathrm{M} \mathrm{NaCl}, 0.015 \mathrm{M}$ Na citrate, $10 \mathrm{mM}$ EDTA, $1 \%$ sarkosyl, and $0.09 \mathrm{mg} / \mathrm{ml}$ proteinase $\mathrm{K}$ (Sigma), and incubated for $2 \mathrm{~h}$ at $50^{\circ} \mathrm{C}$. DNA was then precipitated with $100 \%$ ethanol, and dissolved in Tris-EDTA buffer. An aliquot of DNA was subjected to DNase-free RNase $(0.5 \mathrm{mg} / \mathrm{ml}$, Sigma) treatment for $20 \mathrm{~min}$ at $37^{\circ} \mathrm{C}$, and subjected to electrophoresis on $1.5 \%$ agarose.

\section{Flow cytometry detection of apoptosis}

TGF- $\beta$ treated or untreated cells $\left(3-5 \times 10^{6}\right)$ were collected, washed twice with HBSS buffer (Invitrogen) and stained with LIVE/DEAD Cell Viability Kit (Molecular Probes, Eugene, OR). Cells were simultaneously exposed to cell-permeant, green-fluorescent SYTO 10 and cell-impermeant, red-fluorescent DEAD Red (ethidium homodimer2) nucleic acid stain for $20 \mathrm{~min}$ in the dark and then fixed in freshly prepared $4 \%$ glutaraldehyde and washed as instructed. Stained cells were confirmed with Zeiss AxioVision fluorescent microscope (Carl Zeiss, Inc., Thornwood, NY) and analyzed with Cytomics FC 500 (Beckman Coulter, Fullerton, CA) by Rutgers University NIEHS Analytical Cytometry Core Facility. At least $10^{4}$ events were acquired in list mode and analyzed with Cytomitx RXP acquisition software (Beckman Coulter). All experiments were performed 3 times with S.D. $<5 \%$

\section{RESULTS}

\section{Stable overexpression of Bax in NRP-154 cells}

When GFP-Bax was transfected into NRP-154 cells, no obvious cell death was observed in green fluorescent labeled cells (Fig. 1A and 1D, control). In fact, most of the cells expressing GFP-Bax show intact cell morphology, with a diffuse pattern of green fluorescence consistent with cytosolic localization of GFP-Bax. This result is surprising and suggests that NRP-154 cells can sustain overexpression of GFP-Bax, although GFP-Bax has been shown to have potent pro-apoptotic functions in other cell lines [12]. Translocation of GFP-Bax from cytosol into 


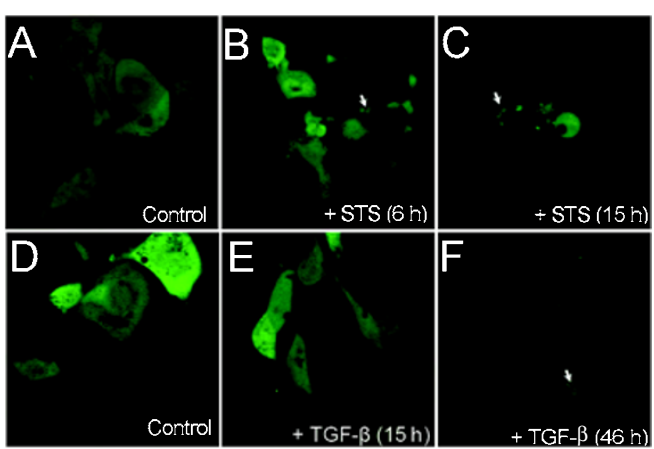

Fig. 1 Induction of intracellular translocation of GFP-Bax by TGF- $\beta$ in NRP-154 cells. GFP-Bax exhibited a cytosolic localization (controls, (A) and (D)). Staurosporin (STS) induced GFP-Bax intracellular membrane partition (arrows in (B) $6 \mathrm{~h}$ and (C) $15 \mathrm{~h}$ of STS treatment). Upon TGF- $\beta$ treatment, GFP-Bax went through a time-dependent translocation to intracellular membranes, which was not seen in $15 \mathrm{~h}$ of TGF- $\beta$ treatment (E) but appeared after $46 \mathrm{~h}$ of TGF- $\beta$ treatment (arrow in $(\mathbf{F}))$.

intracellular membranes became apparent after $46 \mathrm{~h}$ TGF- $\beta$ $(10 \mathrm{ng} / \mathrm{ml})$ treatment and subsequently apoptotic cell death was ensured (Fig. 1F). The pattern of GFP-Bax translocation upon TGF- $\beta$ treatment was very similar to Staurosporin $(2 \mu \mathrm{M})$ induced apoptosis (Fig. 1B and 1C). Staurosporin had been previously shown to induce Bax translocation from the cytosol to cellular membranes [12].

In order to differentiate whether the resistant nature of NRP-154 cells to GFP-Bax is due to the GFP-fusion construct or Bax itself, we transfected cDNA encoding the full-length Bax into NRP-154 cells. Through a series of limited-dilutions under constant selection with hygromycin (a selection marker of the pCEP4 plasmid), we obtained multiple independent clones of NRP-154 cells that exhibited sustained overexpression of Bax. As shown in Fig. 2, Western blot with 6A7 monoclonal antibody against the full-length Bax demonstrated significant overexpression of Bax in cells transfected with pCEP4 (Bax) (clones labelled A through D, Fig. 2). For example, in clone-C, the level of Bax expression is approximately 10 folds higher than that of the endogenous level of Bax expression (lane 1 and 2, Fig. 2).

These cells can be maintained in multiple passages $(>20)$ without apparent decline of their Bax expression. Thus, NRP-154 cells are different from normal non-tumor cells as they can resist sustained and stable overexpression of Bax.

\section{Overexpression of Bax increases sensitivity to TGF- $\beta$-induced apoptosis in NRP-154 cells}

Sustained overexpression of Bax in NRP-154 cells indicates that other co-factors may function to counteract the apoptotic effect of Bax by maintaining it in a latent,

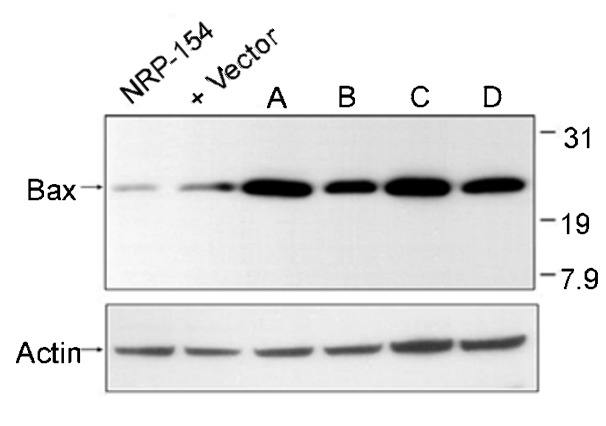

Fig. 2 Stable overexpression of Bax in NRP-154 cells. Control pCEP4 vector, or pCEP4-Bax transfected NRP-154 cells were established. Bax expression level was detected with anti-Bax (6A7) mAb, which detects only the full-length $\operatorname{Bax}(\operatorname{Bax}(\mathrm{p} 21))$. Lane 1 is parental NRP154 , lane 2 is cells transfected with vector, lanes $3-6$ are stable NRP154 (Bax) clones A-D. $\beta$-actin level serves as loading control.

inactive state. The establishment of separate NRP-154 clones with stable overexpression of Bax enables us to test the apoptotic responses of these cells to TGF- $\beta$ using general cell population assays. Our previous studies have shown that TGF- $\beta$ is a potent inducer of apoptosis in NRP154 cells, causing substantial loss of cell numbers within $2-3 \mathrm{~d}$ after treatment [13]. As shown in Fig. 3A, the TUNEL assay revealed apoptotic nature of cell death induced by TGF- $\beta$ is more apparent in NRP-154 overexpressing Bax. Moreover, internucleosomal DNA fragmentation triggered by TGF- $\beta$ could be detected in a DNA laddering assay (Fig. 3B).

The morphological hallmarks of apoptosis including cell shrinkage, changes in intracellular granularity, and condensation of cytoplasm and nucleus have been widely used in the fluorescent activated cell sorter (FACS) assay of apoptosis [14]. Direct assessment of cell death and viability was accomplished using fluorescent probes that stain either live or dead cells (see Methods). As shown in Fig. 4 Right panels, different populations of dead cells (with low SYTO 10 green fluorescence and high ethidium homodimer-2 red fluorescence, population N1) represented in the upper left corner of all plots can be detected in the different clones of NRP-154 cells. The results are entirely consistent with the light-scattering assay shown in Fig. 4 Left panels. To assess the effect of Bax overexpression on the apoptotic signaling of NRP-154 cells, we compared the degree of TGF- $\beta$ triggered apoptosis in the different clones of NRP-154 cells. All the cells exhibited similar extent (less than $5 \%$ ) of cell death in the absence of TGF- $\beta$ (data not shown). However, as shown in Fig. 4, NRP-154 cells overexpressing Bax showed significantly higher 
A
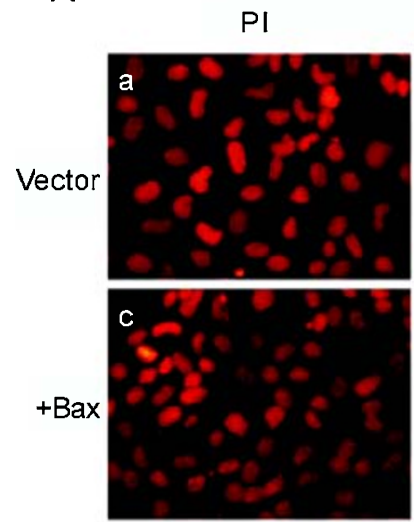

TUNEL
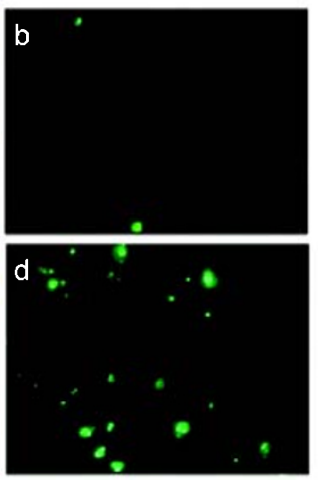

B WT +Vector +Bax TGF- $\beta$

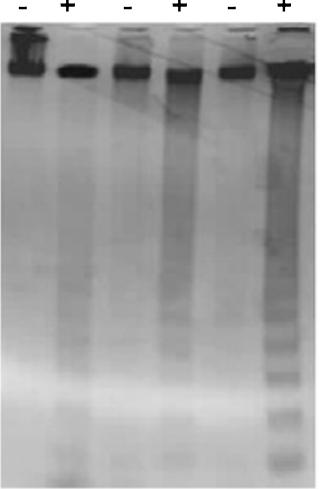

Fig. 3 TGF- $\beta$ induced apoptosis in NRP-154 cells. (A) TUNEL assay. NRP-154 cells stably transfected with vector control (a and b) or overexpressing Bax (c and d) were subjected to TUNEL assay (b and d) and counterstained with Propidium Iodide (a and $\mathbf{c})$. (B) DNA fragmentation assay. DNA extracted from untreated or TGF- $\beta$ treated NRP-154 cells (wt), cells expressing vector (+ vector) and cells overexpressing Bax (+Bax) were subjected to agarose gel electrophoresis and visualized under UV light.

A

B
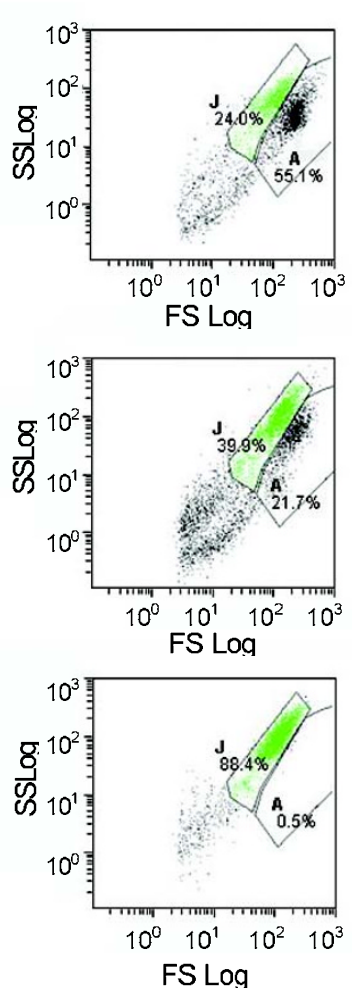

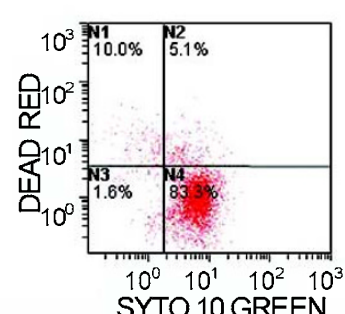

SYTO 10 GREEN
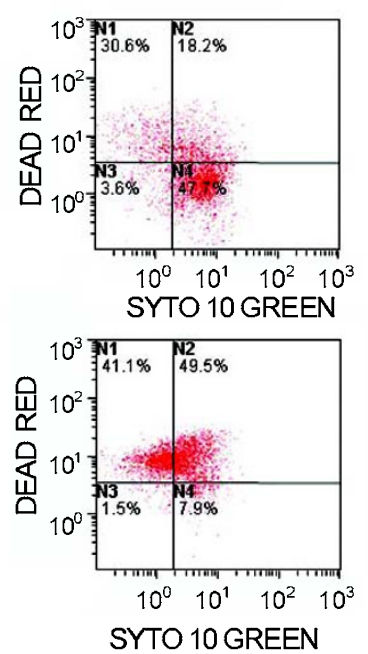

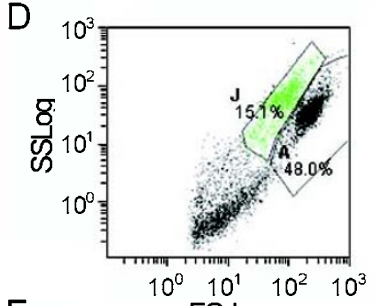

E

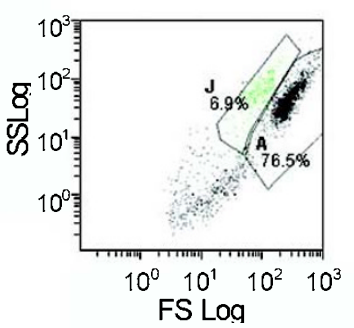

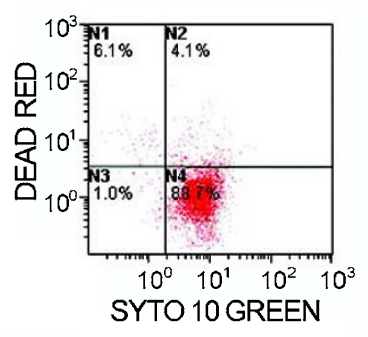

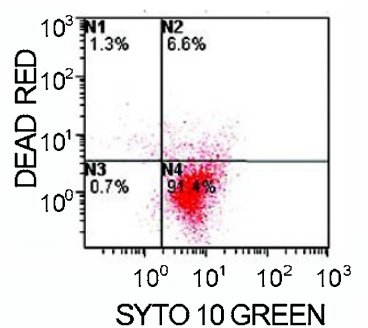

Fig. 4 Induction of apoptosis by TGF- $\beta$ in NRP-154 cells overexpressing Bax cells. Cells were incubated for $48 \mathrm{~h}$ in the presence of $10 \mathrm{ng} / \mathrm{ml}$ TGF- $\beta 1$ and detached by trypsinization. After $20 \mathrm{~min}$ of incubation with Syto 10 GREEN and ethidium homodimer- 2 (DEAD RED), the intracellular fluorescence intensity was measured in a Cytomics FC 500 flow cytometer. Results representative of 3 runs of experiments are shown. Left panels: Apoptotic cells (population J) were defined as cell populations trailed behind the healthy cell population (population A) in light scattering detection. Right panels: Cell viabilities were detected by Syto 10 Green / Dead Red staining. The percentage of live (Syto 10 Green-positive, population N4), dead (Dead Red-positive, population N1) and compromised cells (stained both green and red, population N2) populations are indicated in dot-plot histogram. Population N3 represent background stained cells. Samples shown are (A) vector control cells; (B), (C) and (D) Bax overexpressing clones A, C and D, respectively; (E) Bcl-xL overexpressing clone. 


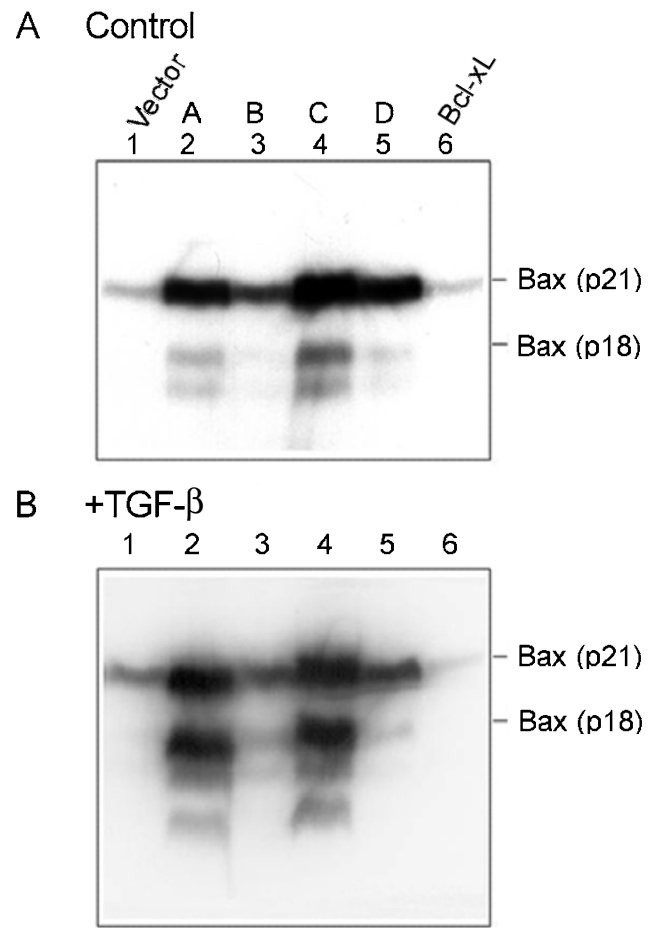

Fig. 5 Bax cleavage during TGF- $\beta$ 1-induced apoptosis in NRP-154 rat prostate cancer cells. (A) Untreated cells. (B) Cells treated with TGF- $\beta(10 \mathrm{ng} / \mathrm{ml})$ for $48 \mathrm{~h}$. The effect on Bax cleavage in NRP-154 cells was determined. Anti-Bax $\Delta 21$ antibody detects all forms of Bax, including both full-length $\mathrm{Bax}(\mathrm{Bax}(\mathrm{p} 21))$ and the cleaved form of Bax (Bax (p18)). Lane 1, vector transfected control cells; lane 2 5, NRP-154 (Bax) clones A-D; lane 6, pCEP4-Bcl-xL transfected NRP-154 cells.

degree of cell death, particularly in clones A and C (Fig. 4B and C), when compared with control cells subjected to selection with mock pCEP4 transfection (Fig. 4A). Interestingly, clones $\mathrm{D}$ display significantly less apoptosis induced by TGF- $\beta$ (Fig. 4D), although their Bax differoverexpression is comparable to those of clones $\mathrm{A}$ and C. As expected, NRP-154 cells stably overexpressing $\mathrm{Bcl}-\mathrm{xL}$ are resistant to TGF- $\beta$ induced apoptosis (Fig. 4E) [13].

Our data therefore indicate that different degrees of sensitivity to TGF- $\beta$ induced apoptosis in NRP- 154 cells are subjected to chronic overexpression of Bax. These ences could reflect the existence of distinct cytosolic mechanisms that counter balance the action of exogenous Bax, or post-translational modifications of Bax may exist in NRP-154 cells that could alter its potency as an apoptotic regulator.

\section{Proteolytic cleavage of Bax during TGF- $\beta$ induced apoptosis in NRP-154 cells}

Proteolytic cleavage of Bax by calpain has been dem- onstrated in a variety of cells undergoing apoptosis. Such posttranslational modification of Bax may occur at the amino terminus, and the cleavage product of $\mathrm{Bax}(\mathrm{p} 18)$ is more potent in inducing apoptosis than full length Bax [68]. Using a polyclonal antibody against Bax, we detected various degrees of Bax cleavage in the different NRP-154 clones. Under control condition, intrinsic cleavage of Bax could be detected in certain clones of NRP-154 cells, e.g. clone $\mathrm{A}$ and $\mathrm{C}$ (Fig. 5A). Following treatment with TGF- $\beta$, the proportion of the $18 \mathrm{kDa}$ cleavage product of $\mathrm{Bax}$ increased significantly (Fig. 5B). Interestingly, a close correlation between the generation of $\mathrm{p} 18$-Bax and apoptotic cell death was observed. Clones A and C, which were more sensitive to TGF- $\beta$ induced apoptosis, showed a higher level of p18-Bax. Clones B and D, which were less sensitive to TGF- $\beta$ induced apoptosis, displayed less p18Bax. These results show a close correlation between Bax cleavage and TGF- $\beta$ induced apoptosis.

\section{DISCUSSION}

Manipulating the function of Bax can alter the balance between cell proliferation and apoptosis, and may serve as a powerful therapeutic approach to prostate cancer. It is known that reduced Bax expression is associated with the apoptotic resistant nature of some prostate cancer cells [15]. Bax overexpression has been shown to confer apoptosis in certain androgen-independent prostate cancer cells including PC3 [16] and LNCap [17] cells in which over 10 fold Bax overexpression induced siginificant cell death. Recent studies have shown that posttranslational modifications of Bax occurs in cells that commit to undergo apoptosis, and such modifications may function as an amplification mechanism to enhance the apoptotic effect of Bax and its co-factors. For example, proteolytic cleavage of Bax by calpain results in the generation of $\mathrm{p} 18$-Bax and a 32 amino acid amino-terminal polypeptide. The p18Bax has been shown to have enhanced pro-apoptotic function in a number of tumor cell lines, such as HL-60 [5], Jurkat $T$ cells [6] and SKOV-3 ovarian cancer cells [7]. It has been proposed that $\mathrm{p} 18$-Bax may function as a BH3domain only protein to modulate apoptosis through its increased affinity for Bcl-xL [9].

In this study, we report three novel findings. First, tumorigenic NRP-154 prostate cancer cells can sustain high level of Bax overexpression without undergoing apoptosis. Second, NRP-154 cells with sustained overexpression of Bax exhibit increased sensitivity to TGF- $\beta$ induced apoptosis. Third, TGF- $\beta$ induced apoptosis of NRP-154 cells show apparent correlation with the $18 \mathrm{kD}$ cleavage product of Bax. Our data suggest that excess Bax in NRP154 cells resides in a latent form that can be proteolytically activated upon discreet stimuli and engage in pro- 
moting the execution of apoptosis. Therefore, NRP-154 could serve as a unique model to study Bax regulation, tumorigenesis and TGF- $\beta$ induced apoptosis in androgenindependent prostate cancer, which may facilitate future studies on the apoptosis resistance mechanisms of certain cancers.

Increasing evidence indicates that the amino-terminus of Bax plays a cytoprotective role by negatively regulating mitochondrial targeting of Bax, through its interactions with cytoplasmic co-factors such as humanin [18], 14-3-3 [19] and $\mathrm{Ku} 70$ [20]. The fact that NRP-154 cells can sustain up to 10 fold Bax overexpression over the endogenous level raises an intriguing possibility that other intrinsic cofactors may exist in NRP-154 cells. These factors may keep Bax in a latent condition and antagonize its apoptotic activity. Such factors could be responsible for the tumorigenic growth of prostate tissue. A better understanding of the possible existence of such molecules will have impact on prostate cancer therapies.

Extensive studies from other cell lines have demonstrated that Bax cleavage is mediated by calpain, a $\mathrm{Ca}^{2+}$-dependent protease with diverse cellular functions. Using DNA microarray assays, we have identified changes in several genes related to the apoptotic signaling pathway. In particular, a specific isoform of calpain, calpain-8, is significantly downregulated in NRP-154 cells with sustained overexpression of Bax. Interestingly, the expression of endogenous caplain inhibitor, calpastatin, is not changed (unpublished result). Thus, it is possible that the altered proteolytic cleavage of Bax may reflect the altered function of caplain, perhaps via its altered $\mathrm{Ca}^{2+}$-dependent activation mechanisms. Since alteration in $\mathrm{Ca}^{2+}$ homeostasis has been shown to induce apoptosis in prostate cancer cells [21], future studies focusing on the cellular and molecular mechanisms underlying the $\mathrm{Ca}^{2+}$-dependent regulation of calpain and the resulting proteolysis of Bax should provide important insights into alternative therapies of prostate cancer.

\section{ACKNOWLEDGEMENTS}

We thank Drs. Yufang SHI and Satish DEVADAS for helpful discussion and technical assistance during the course of this study. This work was supported by a grant of the National Institutes of Health (R01-CA95379) to J. MA and a UMDNJ-Foundation Research Grant (P 14-03) to Z. PAN.

Received, Oct 19, 2004

Revised, Jan 4, 2005

Accepted, Feb 3, 2005

\section{REFERENCES}

1 So AI, Hurtado-Coll A, Gleave ME. Androgens and prostate cancer. World J Urol 2003; 21:325-37. Epub 2003 Oct 29.

2 Wrana JL, Attisano L, Wieser R, Ventura F, Massague J. Mechanism of activation of the TGF-beta receptor. Nature 1994; 370: 341-7.

3 Cory S, Huang DC, Adams JM. The Bcl-2 family: roles in cell survival and oncogenesis. Oncogene 2003; 22:8590-607.

4 Zong WX, Li C, Hatzivassiliou G, et al. Bax and Bak can localize to the endoplasmic reticulum to initiate apoptosis. J Cell Biol 2003; 162:59-69.

5 Wood DE, Thomas A, Devi LA, et al. Bax cleavage is mediated by calpain during drug-induced apoptosis. Oncogene 1998; 17: 1069-78.

6 Gao G, Dou QP. N-terminal cleavage of bax by calpain generates a potent proapoptotic $18-\mathrm{kDa}$ fragment that promotes bcl-2independent cytochrome $\mathrm{C}$ release and apoptotic cell death. $\mathrm{J}$ Cell Biochem 2000; 80:53-72.

7 Yeo JK, Cha SD, Cho CH, et al. Se-methylselenocysteine induces apoptosis through caspase activation and Bax cleavage mediated by calpain in SKOV-3 ovarian cancer cells. Cancer Lett 2002; 182:83-92.

8 Altznauer F, Conus S, Cavalli A, Folkers G, Simon HU. Calpain1 regulates Bax and subsequent Smac-dependent caspase- 3 activation in neutrophil apoptosis. J Biol Chem 2004; 279:5947-57. Epub 2003 Nov 11.

9 Cartron PF, Oliver L, Juin P, Meflah K, Vallette FM. The p18 truncated form of Bax behaves like a Bcl-2 homology domain 3only protein. J Biol Chem 2004; 279:11503-12. Epub 2003 Dec 17.

10 Danielpour D, Kadomatsu K, Anzano MA, Smith JM, Sporn MB. Development and characterization of nontumorigenic and tumorigenic epithelial cell lines from rat dorsal-lateral prostate. Cancer Res 1994; 54:3413-21.

11 Pan Z, Bhat MB, Nieminen AL, Ma J. Synergistic movements of $\mathrm{Ca}(2+)$ and Bax in cells undergoing apoptosis. J Biol Chem 2001; 276:32257-63. Epub 2001 Jun 18.

12 Wolter KG, Hsu YT, Smith CL, et al. Movement of Bax from the cytosol to mitochondria during apoptosis. J Cell Biol 1997; 139: 1281-92.

13 Chipuk JE, Bhat M, Hsing AY, Ma J, Danielpour D. Bcl-xL blocks transforming growth factor-beta 1-induced apoptosis by inhibiting cytochrome $\mathrm{c}$ release and not by directly antagonizing Apaf-1-dependent caspase activation in prostate epithelial cells. J Biol Chem 2001; 276:26614-21. Epub 2001 Apr 24.

14 Darzynkiewicz Z, Li X, Bedner E. Use of flow and laser-scanning cytometry in analysis of cell death. Methods Cell Biol 2001; 66:69-109.

15 Li B, Dou QP. Bax degradation by the ubiquitin/proteasomedependent pathway: involvement in tumor survival and progression. Proc Natl Acad Sci U S A 2000; 97:3850-5.

16 Li X, Marani M, Yu J, et al. Adenovirus-mediated Bax overexpression for the induction of therapeutic apoptosis in prostate cancer. Cancer Res 2001; 61:186-91.

17 Lowe SL, Rubinchik S, Honda T, et al. Prostate-specific expression of Bax delivered by an adenoviral vector induces apoptosis in LNCaP prostate cancer cells. Gene Ther 2001; 8:1363-71.

18 Guo B, Zhai D, Cabezas E, et al. Humanin peptide suppresses apoptosis by interfering with Bax activation. Nature 2003; 423: 456-61.

19 Nomura M, Shimizu S, Sugiyama T, et al. 14-3-3 Interacts di- 
Bax overexpression sensitizes TGF-b induced apoptosis

rectly with and negatively regulates pro-apoptotic Bax. J Biol Chem 2003; 278:2058-65. Epub 2002 Nov 7.

20 Sawada M, Hayes P, Matsuyama S. Cytoprotective membranepermeable peptides designed from the Bax-binding domain of
Ku70. Nat Cell Biol 2003; 5:352-7.

21 Vanoverberghe K, Vanden Abeele F, Mariot P, et al. Ca2+ homeostasis and apoptotic resistance of neuroendocrine-differentiated prostate cancer cells. Cell Death Differ 2004; 11:321-30. 